\title{
Low-cost Air Quality Sensing Process: Validation by Indoor-Outdoor Measurements
}

\section{Hossein Motlagh, Naser}

\section{IEEE}

2020-11-09

Hossein Motlagh , N , Arbayani Zaidan , M , Fung , P L , Li , X , Matsumi , Y , Petäjä , T , Kulmala , M , Tarkoma , S \& Hussein , T 2020 , Low-cost Air Quality Sensing Process:

Validation by Indoor-Outdoor Measurements . in 15th IEEE Conference on Industrial Electronics and Applications (ICIEA2020) . IEEE , pp. 223-228 , IEEE Conference on Industrial Electronics and Applications, Kristiansand, Norway , 09/11/2020 . https://doi.org/10.1109/ICIEA48937.202

http://hdl.handle.net/10138/321751

https://doi.org/10.1109/ICIEA48937.2020.9248348

acceptedVersion

Downloaded from Helda, University of Helsinki institutional repository.

This is an electronic reprint of the original article.

This reprint may differ from the original in pagination and typographic detail.

Please cite the original version. 


\title{
Low-cost Air Quality Sensing Process: Validation by Indoor-Outdoor Measurements
}

\author{
Naser Hossein Motlagh§, Martha Arbayani Zaidanł, Pak L. Fungł, Xinyang Lił, Yutaka Matsumi*, \\ Tuukka Petäjäł, Markku Kulmalał, Sasu Tarkoma \\ $\S$ Department of Computer Science, University of Helsinki, Finland \\ $\ddagger$ Institute for Atmospheric and Earth System Research (INAR), University of Helsinki, Finland \\ * Institute for Space-Earth Environmental Research (ISEE), Nagoya University, Japan \\ $\dagger$ Department of Physics, Faculty of Science, University of Jordan, Amman, Jordan \\ Emails: $\S, \ddagger$ firstname.lastname@ helsinki.fi, * matsumi@nagoya-u.jp, † t.hussein@ju.edu.jo
}

\begin{abstract}
Air pollution is a main challenge in societies with particulate matter $\mathbf{P} \mathbf{M}_{2.5}$ as the major air pollutant causing serious health implications. Due to health and economic impacts of air pollution, low-cost and portable air quality sensors can be vastly deployed to gain personal air pollutant exposure. In this paper, we present an air quality sensing process needed for lowcost sensors which are planned for long-term use. The steps of this process include design and production, laboratory tests, field tests, deployment, and maintenance. As a case study we focus on the field test, where we use two generations of a portable air quality sensor (capable of measuring meteorological variables and $\mathbf{P M}_{2.5}$ ) to perform an indoor-outdoor measurement. The study found that all of the measurements shown to be consistent through validation among themselves. The sensors accuracy also demonstrate to be adequate by showing similar readings compared to the nearest air quality reference station.

Index Terms-Air Quality, Indoor Air Quality, Outdoor Air Quality, Low-cost Sensors, Sensor Validation.
\end{abstract}

\section{INTRODUCTION AND BACKGROUND}

According to the World Health Organization (WHO), air pollution causes 4.2 million deaths every year as a result of exposure to ambient (outdoor) air pollution and 3.8 million deaths every year as a result of household exposure to smoke from dirty cookstoves and fuels [1]. The polluted air consists of various types of pollutants such as particulate matter $\left(\mathrm{PM}_{10}\right.$ and $\left.\mathrm{PM}_{2.5}\right)$, Ozone $\left(\mathrm{O}_{3}\right)$, Nitrogen dioxide $\left(\mathrm{NO}_{2}\right)$, Carbon monoxide (CO) and Sulphur dioxide $\left(\mathrm{SO}_{2}\right)$ [2]. Among these air pollutants, $\mathrm{PM}_{2.5}$ is known to be one of the main components of current air quality indexes [3]. $\mathrm{PM}_{2.5}$ has direct link with human activities [4] and is linked to respiratory problems [5].

The conventional way to measure the air quality including $\mathrm{PM}_{2.5}$ is using city monitoring stations [6]. Thanks to advances on air quality sensing methodologies, there are a large number with variety of portable and low-cost sensors, capable of measuring $\mathrm{PM}_{2.5}$ concentration [7]. The feasibility of large scale deployment and suitability for air pollution sensing using low-cost air quality sensors are investigated in [8].

Due to the increased importance of health and economic impact of air pollution, start-up companies rush to produce affordable air quality sensors known as low-cost sensors. Generally, these sensors are lightweight and portable which

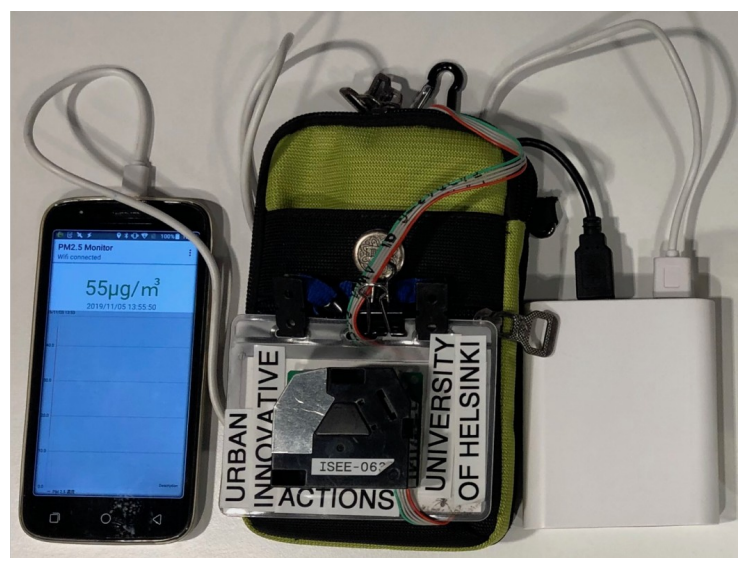

Fig. 1. Portable low-cost sensor unit.

cost few hundreds of dollars rather than tens of thousands of dollars, e.g. air quality monitoring stations [8]. Air quality monitoring stations which are situated at fixed locations provide air quality status at a large scale. In contrast, low-cost and portable sensors are utilized by individuals to track their personal exposure [9]. The application of low-cost sensors for measuring air pollution has increased for air pollution mapping, infrastructure control, and personal exposure monitoring. However, regardless of their application purpose it is essential to validate the sensors performance, because they are known to be less accurate [10].

In literature, some sensor validations are performed after field calibration, whereas in our study the validation is carried out after laboratory calibration. In practice, it is not feasible to test all low-cost sensors next to reference stations for field calibration [11]. Therefore, it is necessary to perform reliable laboratory calibration testings [12]. For example, portable lowcost PM sensors were tested under the condition of steady-state particle mass-concentration [13] or the use of air chamber for validation and calibration $\mathrm{PM}_{2.5}$ [14]. In our paper, we define the Calibration and Validation separately, and we present these two terms within the chain of air quality sensing process. We also introduce a simple approach for validating low-cost air quality sensors through an indoor vs outdoor measurement. 


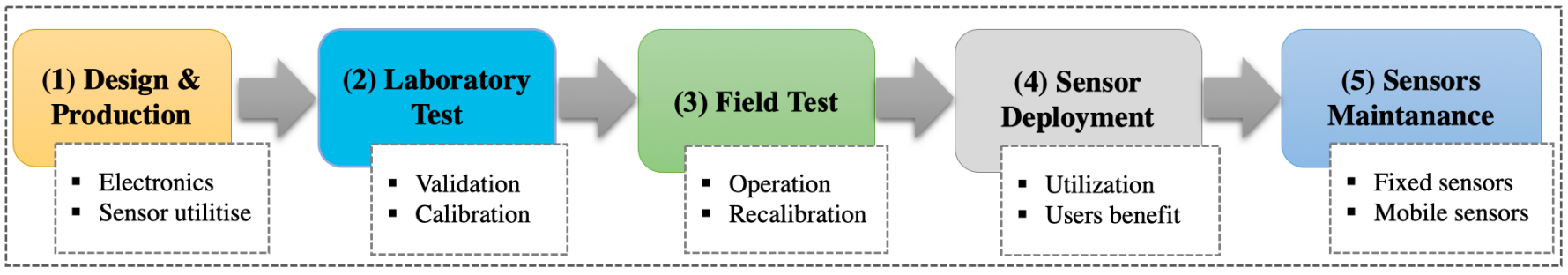

Fig. 2. The requirement and process of air quality sensing using low-cost sensors.

To demonstrate low-cost sensor validation, in this paper we present portable low-cost sensors designed to monitor $\mathrm{PM}_{2.5}$, suitable for indoors and outdoor. Figure 1 displays the sensor device. To prove the suitability of the sensor for air quality measurement, we validate the sensors through an indoor-outdoor experiment. To this end, (1) we present the low-cost sensor devices, designed to measure pressure $(\mathrm{P})$, temperature (T), relative humidity (RH), and $\mathrm{PM}_{2.5}$. (2) We demonstrate that the sensors are consistent and accurate. Whereas, accuracy refers to how well are the measurement of sensor units in agreement with the measurement of a reference station, and consistency indicates how similar are the performance of the two sensors. An experiment was also carried out to compare the sensors measurements against each other and against the air quality monitoring station. The experiment aimed to validate the low-cost sensors by illustrating the accuracy and consistency of their measurements. (3) We show that variation of $\mathrm{PM}_{2.5}$ is linked to human activities indoors and meteorological variables (such as $\mathrm{T}$ and $\mathrm{RH}$ ), outdoors. (4) We also highlight the link between indoor and outdoor pollution concentration using these sensors. (5) Eventually, we conclude the appropriateness of using these low cost sensors for indoor and outdoor air quality measurements, mainly for $\mathrm{P}, \mathrm{T}, \mathrm{RH}$, and $\mathrm{PM}_{2.5}$.

\section{Air Quality Sensing Process}

In principle, the process of air quality measurements using low-cost sensors can be divided into five steps. As shown in Figure 2, these steps include: (1) design and production, (2) laboratory test, (3) field test, (4) sensors deployment, and (5) sensors maintenance. In this section, we explain all of these steps. As a case study our paper demonstrates the field tests step with air quality measurements of five days inside and outside an apartment (hereafter indoor and outdoor).

(1) Design \& Production of air quality sensors are challenging tasks. The design of sensors varies based on their application purposes, sensings, communications and monitoring capabilities. In designing and manufacturing air quality sensors the Electronics and Sensor utilities are the important components for sensing. Sensor board Electronics can be in different sizes depending on the planned sensing, communications, and monitoring capabilities. The Electronics of a sensor can be designed to allow establishing connections through cable and multiple communication technologies such as Bluetooth, Wi-Fi, Zigbee and cellular systems [7], [15]. In addition, the Electronics of a sensor device can be designed to allow equipping various Sensor utilities, and at the same time, resulting in increasing the size of the sensor device as well as the sensor price.

(2) Laboratory Test of a low-cost sensor is performed to assess the reliability and accuracy of the measurements under controlled environment. This step is composed of sensor Validation and Calibration. Sensor Validation confirms the sensor reliability through examining the optimal operational modes of the sensor by evaluating the sensor responses, heating time, temperature and heating pulse mode operation [16]. The Calibration investigates sensor sensitivity, zero condition, responses, and measurement ranges. Sensor sensitivity refers to sensor response per unit, e.g. one ppm of target variable in nominal conditions. Zero condition implies to sensor reading in lab environment with pure air. Sensor response needs to be ideal when the reading of sensor is equal to the target variable in the laboratory. Sensor measurement range pertains to minimum and maximum readings of a sensor. For calibrating a sensor, applying these metrics in the laboratory environment is necessary [12].

(3) Field Test is a crucial step to understand the low-cost sensors performance before deploying them for long-term use. Field test is required to ensure sensor Operation and Field Recalibration. The sensor Operation ensures that at least i) the sensor generates a signal, ii) the sensor is not "flat lining", iii) the sensor emits an expected form of data, and iv) the sensor readings are within a proper range according to the physics of the sensing variables. Field Recalibration ensures that the lowcost sensors provide accurate measurements that is typically known from reference sensing stations [17]. For example, if the sensors start to drift or provide irrational measurements, the comparison between the low-cost sensors and reference sensors will notify the problems. In this case recalibrations or repairs need to be taken into action.

(4) Sensor Deployment attempts to optimize sensor Utilization and Users benefit. The Utilization can be optimized by finding hotspots that are easy to connect to power sources and preserving from environmental impacts such as rain, wind and direct sunlight as well as the safety of sensors in terms of being broken and stolen by people and attacked by animals or birds [17]. The Users benefits can be improved by the impact of air quality information on public lives quality as well as its impact on authorities for making better decisions for example for future city planning.

(5) Sensors Maintenance is needed for the air quality sensors which are deployed for long-term use, for example 
by covering and preserving them from the effect of rain and direct sunlight as well as cleaning their sensing utility from any dust and water vapor. There are two forms which air quality sensor are deployed: Fixed sensors and Mobile sensors. The Fixed sensors are mainly located in fixed and specific locations such as roadsides, bus stops and metro platforms to provide air quality information about the pollution level sourced from vehicles (i.e. traffic); or on buildings in street canyons and different city places with crowd of people. Since, these types of sensors are used to provide information for public, authorities and different organizations could perform the maintenance of these assets. The Mobile sensors comprise portable sensors carried by individuals and are used to monitor personal air pollution exposure in different places. Thus, the maintenance of these low-cost and portable sensors are under the responsibility of individuals and private users.

\section{Sensing Methodology}

\section{A. Sensor Device}

To measure $\mathrm{PM}_{2.5}$, we used sensors of Panasonic model GAl with a thermal resistor to induce an internal upward air flow to facilitate continuous sampling. This sensor unit has an accuracy of $\pm 10 \%$ from low to high concentrations $\left(\sim 1,000 \mu \mathrm{g} / \mathrm{m}^{3}\right)$. It has a life-time over 5 years on continuous measurement, equipped with an auto calibration function [18]. The low-cost sensor units which we used in our experiment are shown in Figure 1, referred to as Sensor Generation I (G1) and Sensor Generation II (G2). These devices are portable sensor units designed to measure $\mathrm{PM}_{2.5}, \mathrm{RH}, \mathrm{T}$ and $\mathrm{P}$. $\mathrm{PM}_{2.5}$ measures the mass concentration of particulate matter of diameter smaller than $2.5 \mu \mathrm{m}$. These sensors are shown in Figure 3(a).

The thermal resistor in the sensor stimulates flow induced by temperature gradient. These sensor devices utilise light-scattering particle (LSP) sensing utilities for monitoring $\mathrm{PM}_{2.5}$. LSP sensors are well-known low-cost solutions for particle concentrations measurements and monitoring. One of the main features of LSP relates to their low power consumption [14], [19]. The sensor devices are also equipped with a WiFi module and mobile phone connectivity for data logging and visualization. The mobile phone provides GPS logging. These types of portable sensor devices are utilised to perform real-time and spatial $\mathrm{PM}_{2.5}$ measurements and monitoring [20]. The sensor G2 has the same hardware as sensor G1. In addition to the capabilities of sensor G1, sensor G2 is equipped with a case to reduce the effect of air turbulence in the inlet. Sensor G2 is also equipped with meteorological sensor utilities including $\mathrm{P}, \mathrm{T}$, and RH. In addition, an algorithm is embedded in sensor G2 to filter the raw measured data such that it removes the spikes before data recording and monitoring.

\section{B. Sensor unit validation}

Generation 1 (G1): In our previous experiment performed in Helsinki [8], we operated the low-cost sensor (G1) next

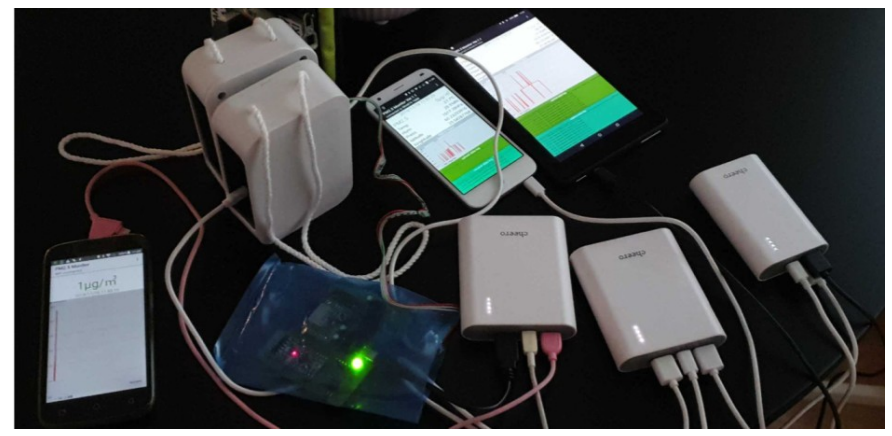

(a) The three low-cost sensor used in our experiment.

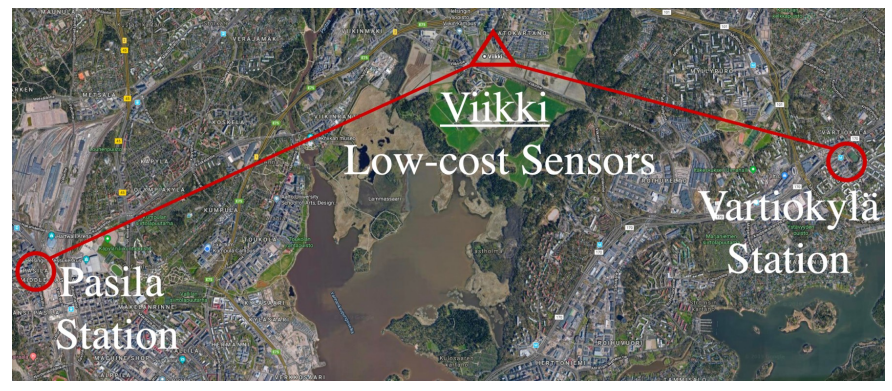

(b) City air quality stations (circles) and low-cost sensors (triangle).

Fig. 3. The measurement sites and experimental setup.

to the SMEAR III ${ }^{1}$ (Station for Measuring EcosystemAtmosphere Relations) which is an accurate reference air quality monitoring station [21], designed for research and scientific exploration. As described in [8], we performed measurements during $8^{\text {th }}$ May - $19^{\text {th }}$ July 2018 (excluding weekends and holidays). There was a total of 44 times of measurements, each time about 2 hours of data recording. The measurements were performed at 1 meter above ground and with a distance of two meters from the SMEAR III station. Sensors were also protected from direct influence of sunlight and wind. We also downloaded the measurements of the SMEAR III for the same period from the open-access data portal $\mathrm{AVAA}^{2}$. Considering the time granularity of SMEAR III data, we aggregated the stored data from the two sensors to one-minute averages. Then, we compared the measurement results of the sensors and SMEAR III and validated the sensors.

Generation 2 (G2): In our current study to validate this sensor generation, we tested the consistency of meteorological variables by comparing the G2 sensors among themselves. The consistency of $\mathrm{PM}_{2.5}$ measurements was compared using two of these sensors, which were placed side by side with sensor G1. The $\mathrm{PM}_{2.5}$ accuracy of the $\mathrm{G} 2$ sensors indoor were evaluated using the sensor G1 which was tested in our previous study [8]. For outdoor measurement, $\mathrm{PM}_{2.5}$ concentration in G2 sensors was compared with the nearest Helsinki Region Environmental Services (HSY) ${ }^{3}$ in Vartiokylä and other meteorological data with Pasila HSY station. The

${ }^{1}$ https://www.atm.helsinki.fi/SMEAR/index.php/smear-iii

${ }^{2}$ https://avaa.tdata.fi

${ }^{3}$ https://www.hsy.fi/en/residents/pages/default.aspx 

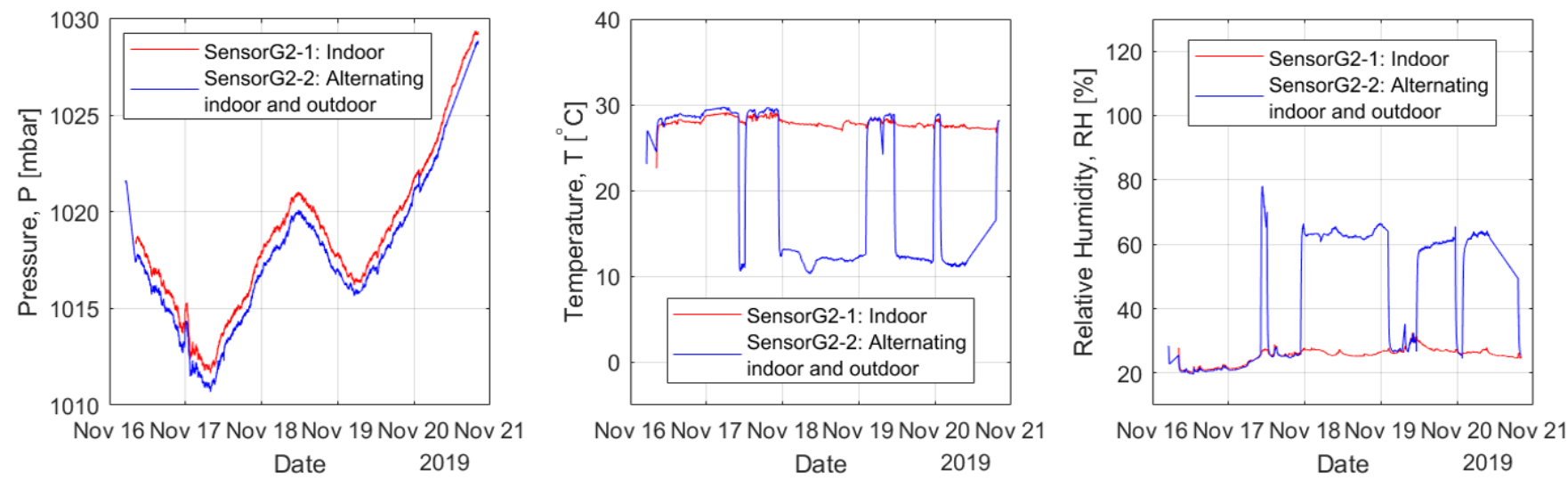

Fig. 4. Time series plots for pressure, temperature, and humidity measurements by sensors.

measurement locations are depicted in Figure 3(b). These stations are described further in IV-A. HSY is a municipal body which produces environmental services and information for Helsinki metropolitan area. HSY owns 11 fixed air quality monitoring sites which carries out air quality measurements. In the following section IV, we explain our experiment in detail.

\section{EXPERIMENTATION RESULTS}

In this section, we describe the validation of low-cost sensors. We explain the environment where the experiment was carried out as well as the experiment results of low-cost sensors through an indoor-outdoor measurement. Then, we compare the performance of the sensors on meteorological and aerosol measurement variables and we investigate the accuracy and consistency of G2 sensors.

\section{A. Environment}

The measurements for this experiment were held in Viikki district in the north-east of city of Helsinki, Finland. The district is 7 to $10 \mathrm{~km}$ from the city centre and hosts more than 10000 inhabitants. Viikki is known to have natural environment where large fields and farmlands are cultivated. Since the year 2000 the population of the district has been increasing steadily which has resulted constructing new apartments, and this serves as a main reason for generating construction dust and $\mathrm{PM}_{2.5}$. Our measurements were carried out continuously in fourth floor of an apartment from $16^{\text {th }}$ to $21^{\text {st }}$ November 2019. During these days, in the district the P, T, and RH were varying between 1007 mbar to 1025 mbar, $-2^{\circ} \mathrm{C}$ to $7^{\circ} \mathrm{C}$, and $80 \%-100 \%$ respectively. In our experiment, we used one G1 sensor and two G2 sensors (hereafter G2-1 and G22 , respectively). We used sensors G1 and G2-1 continuously indoor, while sensor G2-2 was alternating indoor and outdoor. As illustrated in sub-figures of Figure 4, these environment alternations are identifiable.

\section{B. Meteorological sensing}

This sub-section discusses the consistency performance by meteorological variables using G2 sensors. These variables include P, T, and RH. Figure 4 shows the meteorological measurements of sensors G2-1 and G2-2, where G2-1 was located indoor and G2-2 was alternating indoor and outdoor.

1) Pressure $(P)$ : measurements for both sensors demonstrate similar reading which is approximately $1020 \mathrm{mbar}$ equal to one atmosphere (atm) (Figure 4). Therefore, this indicates the consistency in reading of both sensors. This also demonstrates that both sensors function well because the pressure in Helsinki should be approximately 1 atm since the city average elevation is around 26 meter above sea level [22].

2) Temperature (T): measurements for the sensors show almost identical temperature $\left(28^{\circ} \mathrm{C}\right)$ when they were placed inside (Figure 4). This means that temperature of both G2 sensors are consistent. When the sensor G2-2 was taken outdoor, the reading became different than indoor environment.

3) Relative Humidity (RH): measurements of the sensors illustrate (Figure 4), when both of G2 sensors were indoor, they provide approximately the same reading for $\mathrm{RH}$. The average reading for both sensors are equal to $25 \% \mathrm{RH}$. This result demonstrates that both sensors are consistent when they were located side by side.

\section{Aerosol sensing}

This sub-section explains the $\mathrm{PM}_{2.5}$ measurements using all of the three sensors indoor and outdoor (as shown in Figure 5). While, Sensors G1 and G2-1 were always located indoor, sensor G2-2 was alternating indoor and outdoor. Figure 5 shows the results of sensors G1 and G2-1 under indoor condition. It can be seen that the G1 sensor contains many spikes in the measurement data, while the readings by G2-1 have been filtered already internally. Nevertheless, the measurements of both sensors follow similar patterns if the G1 data spikes are filtered. Therefore, the readings of both sensors can be considered to be reliable because the sensor G1 was validated previously in [8].

Figure 5 also shows the comparison between sensor G2-1 that was always located indoor and G2-2 which was alternating indoor and outdoor. There is no difference in readings between the two sensors while both located indoor. This indicates that 

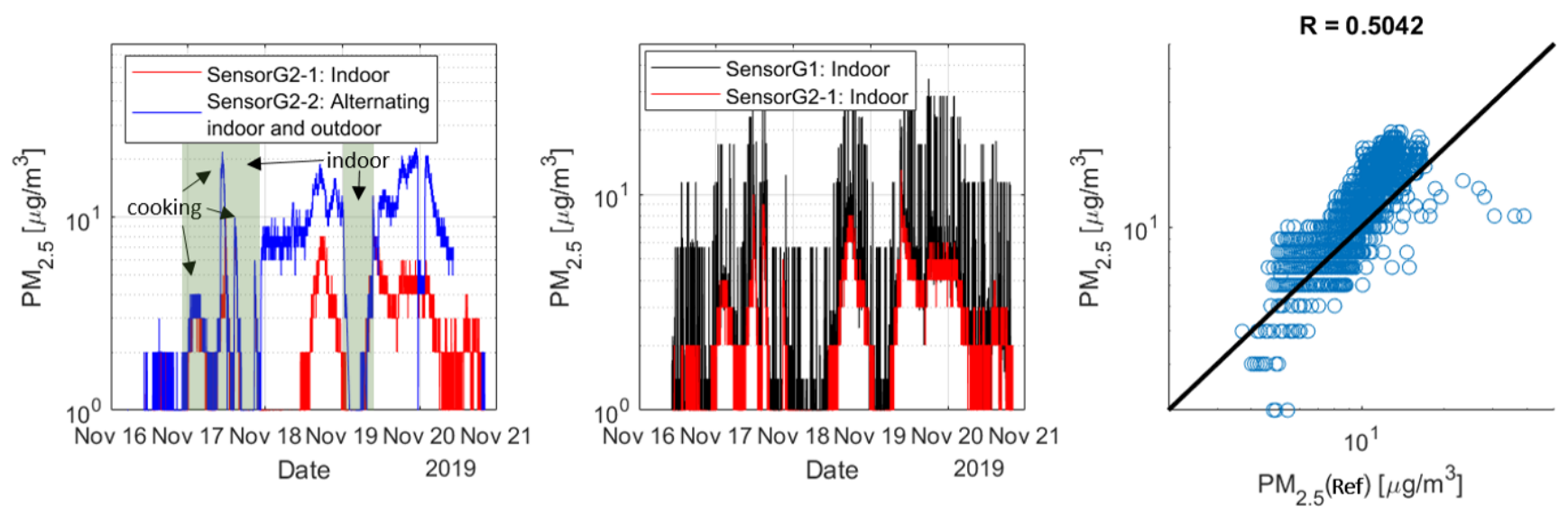

Fig. 5. $\mathrm{PM}_{2.5}$ measurements using portable low-cost sensors indoor and outdoor.

both $\mathrm{G} 2$ sensors are consistent for $\mathrm{PM}_{2.5}$ measurements. In addition, the sensor reading can also be validated through human activities. This was recorded during the measurement period. For example, in the afternoon on $17^{t h}$, the cooking actively has increased the $\mathrm{PM}_{2.5}$ near G2-2 sensor which resulted in an elevated reading. This is shown in Figure 5, when alternating the G2-2 sensor indoor and outdoor. The pollution rise is also slightly illustrated on the same day late at night when warming the food by the experimenter. Figure 5 displays the scatter plot of $\mathrm{PM}_{2.5}$ measurements of the HSY Vartiokylä reference station and the G2-2 sensors. The relationship can be seen to be linear with Pearson correlation coefficient (R) which is equal to 0.5 . In this case, $\mathrm{PM}_{2.5}$ concentration is impacted highly by the long distance between the reference station and the experiment location which is around $7 \mathrm{~km}$.

\section{Summary}

Table I summarizes the daily statistical properties of the experiments from $16^{\text {th }}$ to $20^{\text {th }}$ November 2019. The last column shows the aggregation of all days of the experimental results. The table emphasizes that all indoor measurements are consistent at median of $2.0 \mathrm{\mu g} / \mathrm{m}^{3}$ and mean with approximately to $2.5 \mu \mathrm{g} / \mathrm{m}^{3}$. The standard deviation do not differ a lot, indicating little variations in $\mathrm{PM}_{2.5}$ concentration during the experimental period indoors. The mean of outdoor $\mathrm{PM}_{2.5}$ concentration taken by G2-2 ranged between 10.03 and 14.21 $\mu \mathrm{g} / \mathrm{m}^{3}$. The mean of outdoor $\mathrm{PM}_{2.5}$ concentration taken from the nearest reference station ranged between 6.0 and 9.38 $\mu \mathrm{g} / \mathrm{m}^{3}$. The differences are due to the long distance between the locations of reference station and the low-cost sensors. Indeed, aerosol concentrations vary due to environment, traffic, residential areas and other anthropogenic factors.

\section{DISCUSSION}

Air pollution measurements outdoors using low-cost sensors are typically more challenging than indoors. Indoor pollution level is usually affected by human indoor activities [4], while outdoor measurements are affected by antropogenic outdoor sources (e.g. traffic and industries) and environments (e.g. meteorological parameters and radiation). The best sensor locations known as hotspots are important to be investigated [23]. The meteorological factors such as temperature, pressure, wind and relative humidity are also known to affect low-cost sensors performance [23]. Therefore, it is important to consider these factors before deploying the sensors for longterm use.

Another important challenge in using low-cost sensors relates to measurement accuracy. A general solution is to calibrate low-cost sensors against reference stations [24]. However, the calibration factors may drift over time due to sensor physical wear-out and the changes of environmental conditions. Hence, air pollutant proxies which enable measuring variables to be estimated virtually have become an alternative solution. Then, the proxies can be embedded into low-cost sensors [25]-[28].

To contribute to air pollution databases which typically obtained through remote sensing and model simulation, the deployment of accurate low-cost sensors can also complement air pollution spatiotemporal databases. This opens new challenges and opportunities for scientific investigations in atmosphere, climate research [29], [30] and health related studies, for example, personal exposure estimation.

\section{CONClusions AND Future Work}

This paper presents air quality sensing process needed for low-cost and portable sensors for long-term use. The presented process includes five steps each having related challenges and considerations. These steps include design and production, laboratory tests, field tests, deployment, and sensors and maintenance. As a case study we focus on field test step, where, we use two generations of portable air quality sensors and we perform an indoor-outdoor measurement. The sensors have the capability of measuring $\mathrm{P}, \mathrm{T}, \mathrm{RH}$ and $\mathrm{PM}_{2.5}$. It is found that meteorological variables are consistent and relatively accurate both for indoor and outdoor for the second generation of sensors. The $\mathrm{PM}_{2.5}$ measurements are also shown to be consistent for both sensor generations. Nevertheless, it is difficult to validate the $\mathrm{PM}_{2.5}$ accuracy because the measurements were at distant locations from the reference station. One approach for 
TABLE I

Statistical Description of PM $\mathrm{PM}_{2.5}\left[\mu \mathrm{g} / \mathrm{m}^{3}\right.$ ] MEASUREMENTS BetWeEn $16^{\text {th }}-20^{\text {th }}$ November 2019.

\begin{tabular}{|c|c|c|c|c|c|c|c|c|c|c|c|c|c|c|c|c|c|c|}
\hline \multirow[b]{2}{*}{ Sensing System } & \multicolumn{3}{|c|}{$16^{t h}$} & \multicolumn{3}{|c|}{$17^{t h}$} & \multicolumn{3}{|c|}{$\mathbf{1 8}^{t h}$} & \multicolumn{3}{|c|}{$\mathbf{1 9}^{t h}$} & \multicolumn{3}{|c|}{$\mathbf{2 0}^{t h}$} & \multicolumn{3}{|c|}{ All days } \\
\hline & mean & median & stdv & mean & median & stdv & mean & median & stdv & mean & median & stdv & mean & median & stdv & mean & median & stdv \\
\hline Sensor (G1) & 1.38 & 1.00 & 0.93 & 2.76 & 2.00 & 2.32 & 3.03 & 2.00 & 3.10 & 4.10 & 4.00 & 3.13 & 2.81 & 2.0 & 2.06 & 2.96 & 2.00 & 2.67 \\
\hline Sensor (G2-1) & 0.87 & 1.00 & 0.54 & 2.19 & 2.00 & 1.68 & 2.14 & 1.00 & 2.05 & 3.37 & 4.00 & 1.99 & 2.31 & 2.00 & 1.02 & 2.27 & 2.00 & 1.80 \\
\hline Sensor (G2-2): Indoor & 1.08 & 1.00 & 0.61 & 2.42 & 2.00 & 1.86 & N/A & N/A & N/A & 3.40 & 2.00 & 3.23 & 5.41 & 4.00 & 4.96 & 2.36 & 2.00 & 2.51 \\
\hline Sensor (G2-2): Outdoor & N/A & N/A & N/A & 10.94 & 9.00 & 5.60 & 10.03 & 9.00 & 2.98 & 14.21 & 13.00 & 4.30 & 10.41 & 9.00 & 4.09 & 11.28 & 11.00 & 4.17 \\
\hline Vartiökylä Ref. Station & 6.00 & 5.30 & 1.93 & 7.78 & 6.90 & 2.87 & 9.13 & 9.00 & 2.15 & 9.38 & 9.30 & 6.24 & 7.00 & 6.10 & 2.42 & 7.86 & 7.50 & 3.72 \\
\hline
\end{tabular}

validating the second sensor generation is through comparing them against the first generation which was validated formerly against a highly accurate reference sensing station.

Our future works include developing calibration models and proxies for low-cost sensors and deploying in the field to address aforementioned challenges. We also plan to conduct an extensive study on the chain and steps of sensing process by low-cost air quality sensors.

\section{ACKNOWLEDGEMENTS}

This work is supported by MegaSense and HiDATA programs, Business Finland (6884/31/2018), Academy of Finland (1324576) and HOPE (UIA03-240) projects.

\section{REFERENCES}

[1] World Health Organization, "Air pollution," 2019, accessed 2019-12-03. [Online]. Available: http://origin.who.int/airpollution/en/

[2] F. Costabile, G. Bertoni, F. Desantis, F. Wang, H. Weimin, L. Fenglei, and I. Allegrini, "A preliminary assessment of major air pollutants in the city of suzhou, china," Atmospheric Environment, vol. 40, no. 33, pp. 6380-6395, 2006.

[3] S. M. Bortnick, B. W. Coutant, and S. I. Eberly, "Using continuous pm2. 5 monitoring data to report an air quality index," Journal of the Air \& Waste Management Association, vol. 52, no. 1, pp. 104-112, 2002.

[4] N. H. Motlagh, M. A. Zaidan, E. Lagerspetz, S. Varjonen, J. Toivonen, J. Mineraud, A. Rebeiro-Hargrave, M. Siekkinen, T. Hussein, P. Nurmi, and S. Tarkoma, "Indoor air quality monitoring using infrastructurebased motion detectors," in 2019 IEEE 17th International Conference on Industrial Informatics (INDIN), vol. 1, July 2019, pp. 902-907.

[5] Y.-F. Xing, Y.-H. Xu, M.-H. Shi, and Y.-X. Lian, "The impact of PM2.5 on the human respiratory system," Journal of thoracic disease, vol. 8, no. 1, p. E69, 2016

[6] L. Romo-Melo, B. Aristizabal, and M. Orozco-Alzate, "Air-quality monitoring in an urban area in the tropical andes," IEEE Potentials, vol. 37, no. 1, pp. 34-39, Jan 2018.

[7] A. Bartonova, N. Castell, A. Colette, P. Schneider, M. Viana, M. Voogt, E. Weijers, J. Wesseling, C. Blokhuis, L. Malherbe, L. Spinelle, and A. Gonzalez-Ortiz, "Low cost sensor systems for air quality assessment: Possibilities and challenges," European Environment Agency (European Topic Centre on Air Pollution and Climate Change Mitigation), Tech. Rep., 2019.

[8] E. Lagerspetz, N. H. Motlagh, M. A. Zaidan, P. L. Fung, J. Mineraud, S. Varjonen, M. Siekkinen, P. Nurmi, Y. Matsumi, S. Tarkoma, and T. Hussein, "Megasense: Feasibility of low-cost sensors for pollution hot-spot detection," in 2019 IEEE 17th International Conference on Industrial Informatics (INDIN), vol. 1, July 2019, pp. 1083-1090.

[9] A. Rebeiro-Hargrave, N. H. Motlagh, S. Varjonen, E. Lagerspetz, P. Nurmi, and S. Tarkoma, "Megasense: Cyber-physical system for realtime urban air quality monitoring," in 2020 15th IEEE Conference on Industrial Electronics and Applications (ICIEA), June 2020.

[10] A. Lewis and P. Edwards, "Validate personal air-pollution sensors," Nature News, vol. 535, no. 7610, p. 29, 2016.

[11] N. H. Motlagh, E. Lagerspetz, P. Nurmi, X. Li, S. Varjonen, J. Mineraud, M. Siekkinen, A. Rebeiro-Hargrave, T. Hussein, T. Petäjä, M. Kulmala, and S. Tarkoma, "Toward massive scale air quality monitoring," IEEE Communications Magazine, vol. 58, no. 2, pp. 54-59, 22020.

[12] M. Ionascu, I. Gruicin, and M. Marcu, "Laboratory evaluation and calibration of low-cost sensors for air quality measurement," in 2018 IEEE 12th International Symposium on Applied Computational Intelligence and Informatics (SACI), May 2018, pp. 330-333.
[13] D. Liu, Q. Zhang, J. Jiang, and D.-R. Chen, "Performance calibration of low-cost and portable particular matter (pm) sensors," Journal of Aerosol Science, vol. 112, pp. 1-10, 2017.

[14] Y. Cheng, X. Li, Z. Li, S. Jiang, Y. Li, J. Jia, and X. Jiang, "Aircloud: A cloud-based air-quality monitoring system for everyone," in Proceedings of the 12th ACM Conference on Embedded Network Sensor Systems, ser. SenSys '14. New York, NY, USA: ACM, 2014, pp. 251-265.

[15] C. Lee and J. Lee, "Development of indoor air quality supervision systems using zigbee wireless networks," in 2018 13th IEEE Conference on Industrial Electronics and Applications (ICIEA), May 2018, pp. 9598.

[16] B. Artíñano, A. Narros, E. Díaz, F. J. Gómez, and R. Borge, "Lowcost sensors for urban air quality monitoring: preliminary laboratory and in-field tests within the tecnaire-cm project," in 2019 5th Experiment International Conference (exp.at'19), June 2019, pp. 462-466.

[17] V. Gallart, S. Felici-Castell, M. Delamo, A. Foster, and J. J. Perez, "Evaluation of a real, low cost, urban wsn deployment for accurate environmental monitoring," in 2011 IEEE 8th International Conference on Mobile Ad-Hoc and Sensor Systems, Oct 2011, pp. 634-639.

[18] Panasonic PM Sensor, "Panasonic product specifications: Laser type pm sensor," 2018, accessed 2019-11-04. [Online]. Available: https://industrial.panasonic.com/ww/products/sensors/builtin-sensors/dust-sensor/pm_laser

[19] M. R. Chowdhury, S. De, N. K. Shukla, and R. N. Biswas, "Energyefficient air pollution monitoring with optimum duty-cycling on a sensor hub," in 2018 Twenty Fourth National Conference on Communications (NCC), Feb 2018, pp. 1-6.

[20] T. Nakayama, Y. Matsumi, K. Kawahito, and Y. Watabe, "Development and evaluation of a palm-sized optical PM2.5 sensor," Aerosol Science and Technology, vol. 52, no. 1, pp. 2-12, 2018.

[21] M. Kulmala, "Build a global earth observatory," Nature, vol. 553, pp. 21-23, 012018

[22] S. Lehtonen and S. Luoma, "Incorporating sea level rise scenarios in helsinki city planning," Special Paper-Geological Survey of Finland, vol. 41, p. 83, 2006.

[23] J. S. Apte et al., "High-resolution air pollution mapping with google street view cars: exploiting big data," Environmental science \& technology, vol. 51, no. 12, pp. 6999-7008, 2017.

[24] F. Karagulian, M. Barbiere, A. Kotsev, L. Spinelle, M. Gerboles, F. Lagler, N. Redon, S. Crunaire, and A. Borowiak, "Review of the performance of low-cost sensors for air quality monitoring," Atmosphere, vol. 10, no. 9, p. 506, 2019.

[25] M. A. Zaidan, L. Dada, M. A. Alghamdi, H. Al-Jeelani, H. Lihavainen, A. Hyvärinen, and T. Hussein, "Mutual information input selector and probabilistic machine learning utilisation for air pollution proxies," Applied Sciences, vol. 9, no. 20, p. 4475, 2019.

[26] M. A. Zaidan, D. Wraith, B. E. Boor, and T. Hussein, "Bayesian proxy modelling for estimating black carbon concentrations using white-box and black-box models," Applied Sciences, vol. 9, no. 22, p. 4976, 2019.

[27] M. A. Alghamdi et al., "A predictive model for steady state ozone concentration at an urban-coastal site," International journal of environmental research and public health, vol. 16, no. 2, p. 258, 2019.

[28] P. L. Fung et al., "Input-adaptive proxy for black carbon as a virtual sensor," Sensors, vol. 20, no. 1, p. 182, 2020.

[29] M. A. Zaidan, V. Haapasilta, R. Relan, P. Paasonen, V.-M. Kerminen, H. Junninen, M. Kulmala, and A. S. Foster, "Exploring non-linear associations between atmospheric new-particle formation and ambient variables: a mutual information approach," Atmospheric Chemistry and Physics, vol. 18, no. 17, pp. 12699-12714, 2018.

[30] M. Zaidan, V. Haapasilta, R. Relan, H. Junninen, P. Aalto, M. Kulmala, L. Laurson, and A. Foster, "Predicting atmospheric particle formation days by bayesian classification of the time series features," Tellus B: Chemical and Physical Meteorology, vol. 70, no. 1, pp. 1-10, 2018. 